\section{Career Concerns versus Shared Values: An Empirical Investigation}

\author{
Tom McKenzie ${ }^{1}$ and Alasdair C. Rutherford ${ }^{2}$
}

@SAGE

\begin{abstract}
We study the relationship between career concerns and shared values empirically using employee-employer matched data for the United Kingdom and overtime hours as a proxy for hard work. In line with standard career-concerns theory (Holmström 1982) we find that employees work less overtime, the longer they have been with their current employer. We also find that employees who agree strongly with the statement, "I share many of the values of my organisation" do roughly $20 \%$ more overtime than the rest. Our results suggest the existence of a trade-off between career concerns and shared values. We begin to consider some potential implications of this for employee recruitment as well as for the design of career paths across the private, public and voluntary sectors.
\end{abstract}

JEL classification: J22, J24, L33, M12, M50

\section{Keywords}

Career concerns, pro-social motivation, voluntary sector

\section{Introduction}

Conventional economics implies that rational, utilitymaximising employees need to be motivated to undertake hard work through some form of incentive. The theory of career concerns describes how an employee's implicit incentive to work hard for an employer is stronger earlier in their career because the opportunity to signal talent and influence future wages diminishes over time (Fama 1980; Holmström 1982).

Of course other factors can also influence employee effort, and a growing area of research examines the effect on effort of aligning employee and employer values or goals. One prominent example of this is pro-social motivation in mission-motivated organisations (Besley and Ghatak 2005). It has been well established that there is a relationship between organisational form and pro-social behaviour, with particular consequences for employment relations (Bénabou and Tirole 2006; Besley and Ghatak 2005; Glaeser and Shleifer 2001; Francois and Vlassopoulos 2008).

Our interest lies in exploring how an alignment of values between employer and employee might influence the decision of workers to exert effort at different career stages and how this interacts with the conventional career-concerns literature. In a recent theoretical study, Shchetinin (2012) incorporates the idea of mission alignment into the standard career-concerns model and demonstrates how the incentive to signal talent is weaker for employees who share the values of their employer.

The aim of our paper is to investigate this theoretical trade-off between career concerns and shared values empirically using employee-employer matched data for the United Kingdom from two waves of the Workplace Employment Relations Survey (WERS) in 2004 and 2011. Specifically, we ask whether (1) employees work harder at the beginning of their employment, (2) employees who share the values of their employer work harder than those who do not, (3) hard work then depends less on tenure for employees with shared values, and (4) the shared values incentive dominates the career concerns incentive. We go on to consider whether the relative importance of career concerns and shared values varies across the private, public and voluntary sectors.

The paper is structured as follows. Section 2 discusses the previous career-concerns literature and makes the link between career concerns, effort and shared values. Section 3 describes the theoretical model of Shchetinin (2012) and derives the four hypotheses that we test in this paper. Section 4 describes the dataset that we use and the model that we estimate. Section 5 outlines the results of our analysis, and Section 6 draws a number of conclusions from the results.

\section{Literature Review}

Employers can influence employee effort through an explicit incentive such as pay based on output (Lazear 1986; Gibbons 1987). Alternatively they can use implicit incentives such as the threat of dismissal for underperformance (Shapiro and Stiglitz 1984) or a concern for career progression and the future promise of higher wages within or outside the firm (Fama 1980).

Holmström (1982) demonstrates how such implicit incentives work through the productivity signals that

\footnotetext{
${ }^{1}$ University of Dundee, UK

${ }^{2}$ University of Stirling, UK.

Corresponding author:

Tom McKenzie, University of Dundee, DD1 4HN, Scotland UK.

Email: t.mckenzie@dundee.ac.uk
} 
employees send their current and potential future employers. These incentives are necessarily stronger earlier in an employee's career due to the market learning more about the employee over time and an ever-shortening horizon of future opportunities. Indeed, Gibbons and Murphy (1992) hypothesise that employment contracts are more likely to specify explicit work incentives later in an employee's career. The authors find support for this in Forbes Executive Compensation Survey data.

An empirical challenge in the literature on motivation and incentives is the measurement of employee effort. One of the more observable forms of 'hard work' is the undertaking of additional hours of work. Overtime hours are defined as "actual hours of work in excess of the standard contractual hours" (Hart 2004). Overtime hours may be a voluntary decision on the part of individual employees, or may result from a contractual obligation that employees work additional hours when requested by an employer. However, for most employees, overtime working is a voluntary activity, and not all employees choose to work additional hours (Hart 2004).

Several studies suggest that career concerns are most pronounced for employees undertaking unpaid overtime. For instance Pannenberg (2005) shows that German workers doing unpaid overtime experience $10 \%$ higher wage growth over a ten-year period than other workers. Comparing German and UK data, Bell et al. (2001) report a positive relationship between undertaking unpaid overtime and employee perceptions of their promotion prospects among British workers, although no relationship is found for German workers.

Booth et al. (2003) use overtime hours as a proxy for effort in their analysis of promotions based on firm-specific human capital. ${ }^{1}$ Anger (2008) seeks to separate the pure signalling component of overtime from the effect of additional work hours on the accumulation of human capital. She finds evidence that at least some overtime work leads to higher earnings without increasing productivity, particularly among white-collar workers in West Germany. Employers can exploit the signalling property of work hours for recruitment and promotion purposes. Landers et al. (1996) demonstrated how two large American law firms deliberately set norms of inefficiently long working hours in order to overcome the problem of adverse selection. Only really dedicated employees then choose to work for them because such long hours put off less committed candidates from applying.

Bratti and Staffolani (2007) outline a career-concerns model where workers undertake additional hours of work in order to influence future pay. They analyse British data to show that longer working hours are associated with individuals' perception of promotion chances. Consistent with this, and the relation between working hours and effort, is the finding of Engellandt and Riphahn (2005) that workers on temporary contracts engage in additional hours of unpaid overtime in order to increase the chances of being promoted to a permanent contract.

Akerlof (1982) describes how unpaid overtime can be a form of partial gift-exchange between employees and employers through an implicit contract where workplace norms sustain higher effort in return for wages above the market-clearing rate. A more altruistic form of giftgiving through effort is considered by Gregg et al. (2011) who examine additional hours of work in the pro-socialmotivation context, testing the donated-labour hypothesis in nonprofit organisations by examining data on unpaid overtime. Data from the British Household Panel Survey are used in both cross-section and panel form to test the hypothesis of sector differences in donated labour. The authors find that workers in nonprofit organisations are more likely to donate their labour than those in for-profit firms. They show that this is not due to implicit contracts. The results also suggest that individuals may select into sectors based on their propensity to donate labour.

The growing literature on pro-social motivation explores alternative motivating factors that include non-financial sources of employee utility. One of the key predictions of this literature is that the utility gained from working for a prosocial organisation with which mission-motivated workers share values will form part of the compensation for workers, leading to lower wages paid in nonprofit organisations compared to for-profit companies for equivalent effort (Rose-Ackerman 1997; Besley and Ghatak 2005). The mission-motivated agents in Besley and Ghatak (2005) exert higher levels of effort because they derive 'warm glow' utility from the output. A further theoretical consequence of Besley and Ghatak (2005) is that the different level of effort amongst employees depends on the quality of the match of values between employer and employee. Workers who more closely share the values of their employer have a greater incentive to exert effort without incentive pay.

Empirical work on matching has focused on this match between pro-social motivation and employers. The experiments of Fehrler and Kosfeld (2014) find no significant impact on effort of allowing subjects to choose the mission of their 'employer'. However about a third of subjects are willing to accept lower wages in order to choose a pro-social employer, and these subjects exert significantly higher effort. Gerhards (2015) shows increased effort for mission-matching amongst both students and NGO workers, with more selfish behaviour emerging when the experiment includes repeated interactions. Carpenter and Gong (2016) also show that mission-matching is a strong motivator, and that performance pay has a stronger incentive effect when missions are mismatched. These experiments suggest that while pro-social motivation can influence effort, selection into a pro-social sector is also important. Dur and Zoutenbier (2015) show that altruistic workers sort into missionmotivated employers early in their career using German Socio-Economic Panel data. They also find greater levels of self-reported 'laziness' amongst public sector employees, particularly later in their careers. Dur and Zoutenbier (2015) do not find a clear pattern between altruism (measured by self-report) and job tenure, in contrast with other evidence that altruistic motivation (measured by charitable donations) declines with tenure (Buurman et al. 2012).

The incentives of career concerns and shared values provide different motivations for the allocation of effort through job tenures. Although much of the theoretical and empirical work on shared values has focused on pro-social motivation, the incentive to greater effort could be felt more broadly for employees who share the goals of their employer whatever those goals are. Shchetinin (2012) brings these 
competing motivations together in a theoretical model, and it is this to which we turn next.

\section{Theoretical Framework}

We now present the theoretical model on which our hypotheses are based. Following Shchetinin (2012), the utility function of employee $i$ in period $t$ is

$$
U_{i, t}\left(w_{i, t}, \theta_{i}, y_{i, t}\right)=w_{i, t}+\theta_{i}\left(y_{i, t}-w_{i, t}\right)-C\left(e_{i, t}\right)
$$

where $w_{i, t}$ is $i$ 's fixed wage in period $t$ and $\theta_{i} \in[0,1]$ is the (time-invariant) extent to which her values are aligned with the objectives of her employer. ${ }^{2}$ Her work output in period $t$

$$
y_{i, t}=a_{i}+e_{i, t}+\varepsilon_{i, t}
$$

is the sum of three components: talent $a_{i}$, effort $e_{i, t}$ and random noise $\varepsilon_{i, t}$. $C\left(e_{i, t}\right)$ represents her cost of effort, which is a convex function. Both talent and the noise term are unobservable, drawn from normal distributions and independent from one another

$$
\left[\begin{array}{c}
a_{i} \\
\varepsilon_{i, t}
\end{array}\right] \sim N\left(\left[\begin{array}{c}
\bar{a} \\
0
\end{array}\right], \sum=\left[\begin{array}{cc}
\sigma_{a}^{2} & 0 \\
0 & \sigma_{\varepsilon}^{2}
\end{array}\right]\right) .
$$

Future utility is discounted by $\delta>0$ per period. For simplicity we consider the two-period setting where equilibrium effort $e_{i, t}^{*}$ is characterised by the first-order condition $^{3}$

$$
C^{\prime}\left(e_{i, t}^{*}\right)=\theta_{i}+\left(1-\theta_{i}\right) \cdot(2-t) \cdot \delta \frac{\sigma_{a}^{2}}{\sigma_{a}^{2}+\sigma_{\varepsilon}^{2}} .
$$

Career concerns are represented by the last term on the right-hand side of equation (1). Intuitively, since there are two periods, the employee can work hard in the first period to suggest high talent and increase her value to employers in the second period. These career concerns play a greater role, the more important the future (the higher is $\delta$ ) and the more uncertainty surrounds the employee's talent (the greater $\sigma_{a}^{2}$ in relation to $\sigma_{\varepsilon}^{2}$ ). This is the standard career-concerns result whereby employees work hard early in their careers in order to influence employer beliefs about their ability, and hence future wages, the greater the range of abilities (Holmström 1982). ${ }^{4}$ We thus state our first hypothesis.

Hypothesis 1. Employees work harder earlier in their careers.

Shared values affect employee effort in both a positive and a negative way. On the one hand employees who share their employers' values (those with high $\theta_{i}$ ) expend more effort because they derive utility from the net benefit of their effort to the employer (output less wages). This forms the basis for our second hypothesis.

Hypothesis 2. Employees who share the values of their employers work harder than those who do not.

On the other hand the implicit incentive to work hard in order to influence employer beliefs and increase future wages is weaker for employees who share their employers' values. This is because an employee who cares ${ }^{5}$ about net benefit to the employer also recognises that an increase in wages will reduce that net benefit. Career concerns are thus less important for an employee who shares the values of her employer. We base our third hypothesis on this theoretical result.

Hypothesis 3. Hard work depends less on tenure with the employer for employees who share the values of their employers.

The overall effect of shared values on effort depends how strong career concerns are in the first place. Shchetinin (2012) describes the possibility of observing "performance reversal' for workers sharing values, where the reduction in effort from removing the career concerns incentive is greater than the gain in effort from sharing values. If the future is not important or there is not much uncertainty surrounding employee talent and thus less potential to influence future wages then shared values will have a positive overall effect on effort. However if the implicit incentive to work hard in order to increase future wages is strong enough then the direct positive effect of shared values on effort will be outweighed by their indirect diminishing effect on career concerns. Which effect dominates is ultimately an empirical question, and forms the basis of our fourth hypothesis.

Hypothesis 4. The effect of shared values outweighs the effect of career concerns.

We now go on to describe the data and methods that we use to test these four hypotheses.

\section{Data and Empirical Methods}

We use data from two waves of the UK Workplace Employment Relations Survey (WERS), pooled for the years 2004 and 2011. WERS is an employer-employee linked nationally representative survey of organisations covering the state of employment relations and working life inside British workplaces. Employers are drawn as a stratified random sample, and data are collected on finances, staffing and employment policies and practices within the organisation. A random sample of up to 25 employees from each workplace is then drawn, who each complete an individual worker questionnaire. The data we use in this paper are drawn primarily from the individual worker questionnaire, with organisation characteristics from the management questionnaire.

We explore the extent to which employees share their employer's values without determining what those values are. The values of an organisation are a fairly abstract concept and are challenging to measure (Meglino and Ravlin 1998). We focus on the employee's own perception of the match with their employer's values. O'Reilly and Chatman (1986) found that self-reported measures of organisational values were correlated with pro-social behaviour within organisations, but they acknowledge the difficulties of demonstrating a causal link. Combining data from both the WERS employee and management questionnaires, at the organisation level we do find a strong positive association between employees' reports of sharing values and managers' perceptions of value sharing (Kendall's tau-b coefficient of $0.16 ; p<0.001)$. However, as we do not observe employees longitudinally we are not able to model how the sharing of values might evolve over time. In particular we cannot 
rule out that shared values are developed as a result of the high levels of effort expended during an employee's tenure, although we do not find a strong association between length of tenure and levels of shared values.

We use two survey questions about perceived work intensity to explore overtime working as a proxy for effort, without directly observing a measure of effort. Employees are asked how strongly they agree with the statement that "my job requires that I work very hard". Individuals who agree strongly with this statement work on average $50 \%$ more overtime hours than those who do not. The 2011 wave of WERS also includes a question to employees about whether "people in this workplace who want to progress have to put in long hours" that nicely captures the employee perception of the relationship between working hours and career progression using a Likert scale of agreement. We model this variable for the 2011 subsample using an ordered logistic regression to describe employees' perceptions of career concerns controlling for having to work hard, working hours and workplace tenure. ${ }^{6}$ Employees who are earlier in their careers with their current employer are more likely to agree that long hours are required to progress in their organisation than those with longer tenures. Weekly hours and reporting that their job requires working hard are positively associated with employees being more likely to agree that long hours are required. Although we cannot measure employee effort directly, this descriptive analysis supports the relationship between working hours, hard work and employees' concerns for future advancement.

We thus operationalise hard work as integer hours of overtime measured through the employee questionnaire. Differences in working patterns mean that both the levels and prevalence of overtime working vary between occupations. In order to account for this, individuals' hours are evaluated relative to the mean overtime hours worked in the occupation (UK Standard Occupational Classifications 2000) during that year (2004 or 2011). Average overtime hours are evaluated at the unit group level where there are 353 possible occupational classifications, of which 339 are represented in our WERS sample. In order to avoid skewed estimates for occupational groups with small sample sizes, the average overtime is estimated with a multilevel random effects model of overtime hours $o_{i j k l m}$ for individual $i$ with four levels for the major $(j)$, sub-major $(k)$, minor $(l)$ and unit $(m)$ group occupations respectively,

$$
\begin{aligned}
o_{i j k l m}= & \beta_{0}+\text { major }_{j}+\text { submajor }_{j k}+ \\
& \text { minor }_{j k l}+\text { unit }_{j k l m}+u_{i}
\end{aligned}
$$

where

$$
\begin{gathered}
i \in\{1, \ldots, n\}, j \in\{1, \ldots, 9\}, k \in\{1, \ldots, 25\}, \\
l \in\{1, \ldots, 81\}, m \in\{1, \ldots, 339\} .
\end{gathered}
$$

The estimate of unit group occupation average overtime is therefore

$$
\begin{aligned}
& \widehat{o}_{j k l m}=\widehat{\beta_{0}}+\widehat{\text { major }}_{j}+\text { submajor }_{j k}+ \\
& \widehat{\text { minor }}_{j k l}+\widehat{\text { unit }}_{j k l m} \text {. }
\end{aligned}
$$

This has the desirable property that estimates from small groups are 'shrunken' towards the mean of the higher level groups reducing their sensitivity to outliers in small samples (Snijders and Bosker 2011; McGovern et al. 2007).

'Strongly shared values' is a binary measure of whether employees agree strongly with the statement, "I share many of the values of my organisation." 'Tenure' is a measure of the number of years employed at the same workplace, coded as a metric variable by taking the midpoint of each category. ${ }^{7}$ The interaction of tenure and shared values is generated as the product of the two variables. We then implement a Tobit model, to account for the left-censoring of overtime hours, of the form

$$
h_{i}^{*}=\beta_{0}+\beta_{1} \tau_{i}+\beta_{2} v_{i}+\beta_{3} v_{i} \cdot \tau_{i}+\mathbf{X}_{\mathbf{i}}{ }^{\prime} \boldsymbol{\Gamma}+u_{i}
$$

where the latent variable $h_{i}^{*}$ is the natural logarithm of

employee overtime hours

mean overtime hours for occupation and year

$\tau$ denotes tenure, $v$ stands for strongly shared values, $\mathbf{X}$ is a vector of other variables influencing overtime hours (wages, part-time working, employment sector, trade-union membership, gender, age and family status) and $u$ is an error term. We expect to find $\hat{\beta}_{1}<0$ (Hypothesis 1: direct career-concerns effect), $\hat{\beta}_{2}>0$ (Hypothesis 2: direct effect of shared values), $\hat{\beta}_{3}>0$ (Hypothesis 3 : mitigating effect of shared values on career concerns), and $\hat{\beta}_{1}+\hat{\beta}_{3}=0$ (Hypothesis 4: no 'performance reversal' effect).

\section{Results and Discussion}

\subsection{Descriptive Statistics}

Descriptive statistics for the main variables are subdivided by employment sector ${ }^{8}$ and presented in Table 1 . Roughly half of the employees sampled engage in overtime working. This proportion is slightly lower for public-sector employees. On average, those undertaking overtime do between 3 and 4 hours per week, while slightly more overtime is reported in the private sector than in the other sectors. However as a proportion of weekly contractual hours there is little difference: part-time work, defined as contractual hours of between 0 and 30 per week, is most common in the voluntary sector where over one third of employees fall into this category, compared with one fifth of private-sector employees. ${ }^{9}$

There are differences in the demographic characteristics of employees across the sectors. The voluntary and public sectors are predominantly female $(70 \%$ and $65 \%$, respectively) whereas just over half of employees in the private sector are male. Employees in the private sector tend to be younger and are less likely to be married or cohabiting with a partner. A higher proportion of employees in the voluntary sector are aged 60 and over (9\% compared with 5 to $6 \%$ in the other sectors) and thus fewer voluntary-sector workers care for children aged 18 or under.

The proportion of employees supervising others as a part of their day-to-day duties is broadly similar across all sectors, at just over one third. Unsurprisingly, trade-union membership is significantly higher in the public sector $(63 \%)$ than in the private and voluntary sectors $(23 \%$ and $28 \%$ respectively). Employees in the public sector also tend to have worked the longest for their current employers. 
Table 1. Descriptive statistics

\begin{tabular}{lccc}
\hline \hline \multirow{2}{*}{ Variable } & \multicolumn{3}{c}{ Sector } \\
public & voluntary \\
\hline overtime hours $>0$ & 0.499 & $0.475^{*}$ & 0.497 \\
overtime hours & $(0.500)$ & $(0.499)$ & $(0.500)$ \\
& 3.644 & $3.365^{*}$ & $3.347^{*}$ \\
tenure (years) & $(5.878)$ & $(5.959)$ & $(5.387)$ \\
& 5.784 & $6.697^{*}$ & 5.707 \\
strongly shared & $(4.277)$ & $(4.307)$ & $(4.189)$ \\
values & 0.123 & $0.146^{*}$ & $0.229^{*}$ \\
observations & $(0.328)$ & $(0.353)$ & $(0.420)$ \\
\hline Source: UK Workplace Emp & 21,937 & 13,148 & 2,675 \\
\hline
\end{tabular}

Source: UK Workplace Employment Relations Survey 2004, 2011

Notes: (1) Sample standard deviations in parentheses.

$(2)$ * significantly different from the private sector (two-sample t-tests; $p<0.05$ ).

Strikingly, as shown in Table 1, nearly double the proportion of employees in the voluntary sector $(23 \%)$ agrees strongly with the statement, "I share many of the values of my organisation," compared with private-sector workers $(12 \%)$. The proportion sharing values in the public sector lies in between but closer to the private sector at $15 \%$. Average wage levels are also similar for employees in the private and public sectors but are somewhat higher than levels in the voluntary sector. ${ }^{10}$ Taken together, these figures suggest a selection of mission-motivated employees into the voluntary sector, reflecting the well-established relationship between organisational form and pro-social behaviour mentioned in Section 1. Having considered the WERS data at the descriptive level we turn next to our empirical model to test our hypotheses.

\subsection{Regression Analysis}

Our main results are presented in Table 2. In the first column (model 1) we only control for wage levels, part-time working and year beyond the main variables of interest (tenure and strongly shared values). In the second column (model 2) we then introduce sector controls and account for tradeunion membership, foremanship (supervisor) as well as demographic characteristics. In columns 3 and 4 we separate the empirical analysis by gender and in column 5 we restrict it to the voluntary sector.

We find support for our first three hypotheses in model 1. In line with standard career-concerns theory (Holmström 1982) we find that employees work less overtime, the longer they have been with their current employer (Hypothesis 1: $\left.\beta_{1}<0\right)$. We also find that employees who agree strongly with the statement, "I share many of the values of my organisation" do roughly $20 \%$ more overtime than the rest (Hypothesis 2: $\beta_{2}>0$ ). Moreover our positive estimate for the coefficient on the interaction of strongly shared values and tenure indicates that for these mission-aligned employees the career-concerns effect is reduced by more than half (Hypothesis 3: $\beta_{3}>0$ ). This evidence is consistent with the model by Shchetinin (2012) which introduces shared values into a standard career-concerns framework.
The results are robust to controls for other factors that are known to influence the decision to undertake overtime, including gender, age, family status and tradeunion membership (model 2). When separating the analysis by gender (models 3 and 4) the standard career concerns result holds (Hypothesis 1) but it can be seen that the sharedvalues results (Hypotheses 2 and 3) are stronger among the female subsample (model 3) while the evidence is not statistically significant for the (smaller) male subsample (model 4). Nevertheless the signs on the coefficients are the same in both columns and the relative magnitudes of the coefficients on tenure and the interaction of tenure with strongly-shared-values are similar. ${ }^{11}$ While the results for the voluntary subsector (model 5) are statistically insignificant the magnitude and direction of the coefficient estimates are comparable with those in column 2 so the insignificance is likely due to the smaller sample. A further specification using binary controls for tenure categories instead of our metric tenure variable, including the corresponding interactions with strongly shared values, indicates that shared values compensate for the lack of implicit incentives among longerterm employees (those with tenure of ten years and over), providing further support for Hypothesis 3. ${ }^{12}$
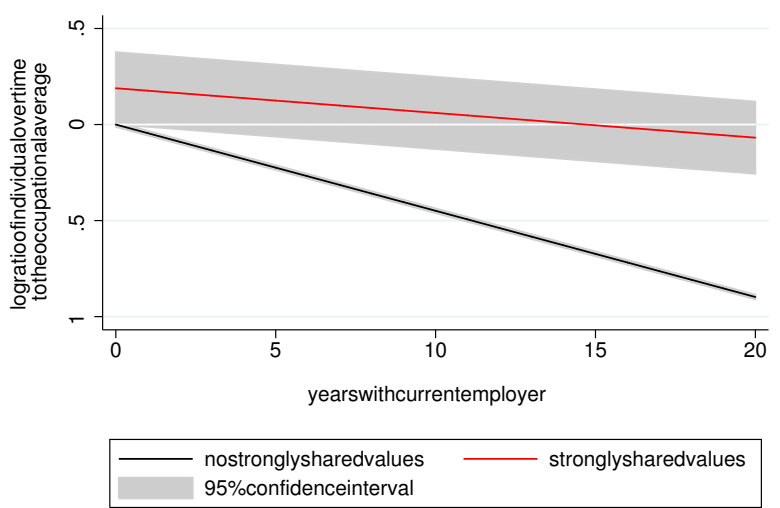

Source:UKWorkplaceEmploymentRelationsSurvey2004,2011

Figure 1. Effect of shared values on career concerns

Our fourth hypothesis concerns whether the direct positive effect of shared values on effort could be outweighed by the indirect diminishing effect of shared values on the implicit career-concerns incentive to work hard. In order to check whether this is the case empirically we conduct post-estimation linear-combination tests. These tests reveal that the hypothesis $\beta_{1}+\beta_{3}=0$ cannot be rejected at the $5 \%$ level for any of our specifications. This means that for employees with strongly shared values there is no statistically significant difference between overtime hours at different levels of tenure. However employees with shared values do undertake significantly more overtime than those without, ceteris paribus (Hypothesis 2). The effect of shared values on career concerns is shown in Figure 1 where the partial effect of shared values on our measure of overtime is plotted against tenure. It can be seen that, all else equal, employees with strongly shared values work more overtime hours than others in their occupation, across different lengths 
Table 2. Tobit regressions

\begin{tabular}{|c|c|c|c|c|c|}
\hline & 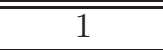 & 2 & 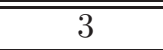 & $\overline{4}$ & 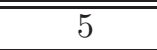 \\
\hline tenure & $\begin{array}{c}-\mathbf{0 . 0 4 8}^{* *} \\
(0.006)\end{array}$ & $\begin{array}{c}-\mathbf{0 . 0 4 5}^{* *} \\
(0.006)\end{array}$ & $\begin{array}{c}-\mathbf{0 . 0 5 2}^{* *} \\
(0.009)\end{array}$ & $\begin{array}{c}-\mathbf{- 0 . 0 3 6}^{* *} \\
(0.008)\end{array}$ & $\begin{array}{c}-0.044 \\
(0.023)\end{array}$ \\
\hline $\begin{array}{l}\text { strongly shared } \\
\text { values }\end{array}$ & $\begin{array}{c}\mathbf{0 . 2 3 5}^{*} \\
(0.094)\end{array}$ & $\begin{array}{l}\mathbf{0 . 1 8 9}^{*} \\
(0.095)\end{array}$ & $\begin{array}{c}\mathbf{0 . 2 7 6}^{*} \\
(0.137)\end{array}$ & $\begin{array}{l}0.113 \\
(0.132)\end{array}$ & $\begin{array}{l}0.336 \\
(0.267)\end{array}$ \\
\hline $\begin{array}{c}\text { strongly shared } \\
\text { values } \cdot \text { tenure }\end{array}$ & $\begin{array}{r}\mathbf{0 . 0 3 7}^{* *} \\
(0.012)\end{array}$ & $\begin{array}{r}\mathbf{0 . 0 3 2}^{* * *} \\
(0.012)\end{array}$ & $\begin{array}{c}\mathbf{0 . 0 3 8}^{*} \\
(0.018)\end{array}$ & $\begin{array}{l}0.021 \\
(0.017)\end{array}$ & $\begin{array}{l}0.025 \\
(0.038)\end{array}$ \\
\hline wage level & $\begin{array}{r}\mathbf{0 . 3 9 3}^{* *} \\
(0.009)\end{array}$ & $\begin{array}{r}\mathbf{0 . 3 4 8}^{* *} \\
(0.010)\end{array}$ & $\begin{array}{c}\mathbf{0 . 3 5 8}^{* *} \\
(0.014)\end{array}$ & $\begin{array}{c}\mathbf{0 . 3 2 6}^{* *} \\
(0.015)\end{array}$ & $\begin{array}{c}\mathbf{0 . 3 0 4}^{* *} \\
(0.037)\end{array}$ \\
\hline $\begin{array}{l}\text { part-time } \\
(\leq 30 \text { hours/week })\end{array}$ & $\begin{array}{l}\mathbf{0 . 1 8 8}^{*} \\
(0.073)\end{array}$ & $\begin{array}{c}\mathbf{0 . 3 1 3}^{* * *} \\
(0.077)\end{array}$ & $\begin{array}{c}\mathbf{0 . 2 5 6}^{* *} \\
(0.094)\end{array}$ & $\begin{array}{c}\mathbf{0 . 5 9 8} \\
(0.135)\end{array}$ & $\begin{array}{l}0.274 \\
(0.248)\end{array}$ \\
\hline year $=2011$ & $\begin{array}{r}-0.112 \\
(0.057)\end{array}$ & $\begin{array}{l}-0.047 \\
(0.058)\end{array}$ & $\begin{array}{r}-0.038 \\
(0.074)\end{array}$ & $\begin{array}{c}-0.059 \\
(0.077)\end{array}$ & $\begin{array}{c}-0.163 \\
(0.202)\end{array}$ \\
\hline Additional controls & no & yes & yes & yes & yes \\
\hline Constant & $\begin{array}{c}-\mathbf{6 . 1 4 5}^{* *} \\
(0.111)\end{array}$ & $\begin{array}{c}-\mathbf{6 . 0 4 6}^{* *} \\
(0.130)\end{array}$ & $\begin{array}{c}-\mathbf{6 . 3 9 2}^{* *} \\
(0.172)\end{array}$ & $\begin{array}{c}-\mathbf{5 . 4 4 5}^{* *} \\
(0.190)\end{array}$ & $\begin{array}{c}-\mathbf{5 . 4 6 6}^{* *} \\
(0.453)\end{array}$ \\
\hline Pseudo $R^{2}$ & 0.029 & 0.033 & 0.034 & 0.026 & 0.033 \\
\hline Observations & 39,619 & 37,760 & 20,644 & 17,116 & 2,675 \\
\hline Left-censored obs. & 20,288 & 19,248 & 11,547 & 7,701 & 1,345 \\
\hline Employer clusters & 3,627 & 3,618 & 3,318 & 3,098 & 251 \\
\hline
\end{tabular}

Notes:

(1) Dependent variable: $\ln \left(\frac{\text { employee overtime hours }}{\text { mean overtime hours for occupation and year }}\right)$

(2) Standard errors in parentheses, adjusted for clustering by employer

(3) Separate estimations by gender in models 3 (female) and 4 (male).

(4) Separate estimation for the voluntary sector in model 5.

(5) Additional controls: sector (models $2-4$ ), trade-union membership, foremanship, gender (models $2 \& 5$ ), age group, marital status, dependent children.

Reference group in model 2: working in private sector, female, aged $40-49$,

married/cohabiting, no dependent children.

Reference group in models 3 and 4 : working in private sector, aged $40-49$,

married/cohabiting, no dependent children.

Reference group in model 5: female, aged $40-49$, married/cohabiting,

no dependent children.

$(6){ }^{* *}\left({ }^{*}\right)$ denotes statistically significant difference from zero at the $1 \%(5 \%)$ level. 
of tenure. In other words, the diminishing effect of shared values on the implicit career-concerns incentive to work hard does not outweigh their direct positive effect on effort so we do not witness performance reversal within our sample. However the relationship between overtime and tenure is only weak for mission-motivated employees, while those without strongly shared values work fewer hours of overtime as their tenure increases (Hypothesis 1).

\subsection{Discussion}

Shchetinin (2012) also considers a potential information asymmetry surrounding shared values whereby employees have superior knowledge of the extent to which they align with employer objectives. Under such conditions employees have an additional implicit incentive to signal a higher level of shared values in order to influence future wages. The theory predicts that it will be easier for truly aligned types to signal their shared values and be distinguishable from others, the lower the proportion of aligned types in the population. We observe relatively low proportions of between just one tenth and a quarter of employees with strongly shared values in our sample, depending on employment sector, which suggests that so-called 'signal-jamming' by unaligned types should not be a significant problem. Nevertheless it would be interesting to investigate the signalling of values further in future work.

Given our evidence that shared values are associated with higher employee effort, an obvious question from an employer perspective is whether, and the extent to which, employee values can be cultivated to bring them into line with organisational objectives. Akerlof (1983, p. 55) suggests exactly this when referring to 'loyalty filters,' stating that an agent's loyalty "may not only be chosen by himself [...] but instead by another agent acting in his own selfish interest, such as [...] an employer interested in extracting unselfish performances from his employees." Indeed, in subsequent work the observation is made that management policy strives to affect the alignment of employer and employee values: "Current theories of management emphasize management's role in changing employee objectives [...]. Aligning the objectives of workers and management is the goal in Management by Objective, where employees are given a role in setting their own goals" (Akerlof and Kranton 2005, p. 20). While this may of course still be possible, we do not find any evidence for it in our sample of employers and employees; our measures for shared values and employee tenure are not significantly correlated. However the proportion of employees with strongly shared values does increase with age. It would thus appear that there is greater selection of individuals into jobs with employers with whom they share values, and better employer-employee matching at later stages of an individual's whole career, while there is less direct influencing by employers of their incumbent employees' values. In order to test for this satisfactorily we would need panel data at the individual level to follow the same workers and the development of their values over time. ${ }^{13}$

A further limitation of relying on cross-sectional data on employees is that we cannot directly account for the effects of unobserved events in their careers. To the extent that these are randomly distributed they would not bias our results.
However, one example that is worth considering is the effect of maternity leave on the career profiles of women both in having an effect on the length of their tenure and as a signal to employers of family intentions. Buligescu et al. (2009) find a significant wage penalty for women following maternity leave using German data, but the effect diminishes within two to three years. Manchester et al. (2008) offer some evidence that wage penalties are due to employers interpreting maternity leave as a signal of lower commitment rather than due to reductions in effort. As such this may suggest that spells of maternity leave could interfere with the shared values signal but that the effect is likely to be relatively short-lived within an employment spell.

We have chosen to derive our hypotheses from a theoretical model (Shchetinin 2012) according to which the sharing of values compensates employees for their career and monetary wage progression. In this model career concerns are nevertheless still present for employees who share values. Yet it is plausible that employees who share values with their employers are simply less interested in monetary gain, not considering the negative impact of higher wages on their employer and instead sharing joint concerns with them about issues such as the environment or politics. ${ }^{14}$ This would lead to similar hypotheses about shared values and effort without relying on the career concerns mechanism.

Overall, we have found evidence of different tenure-effort profiles for employees who agree strongly that they share many of the values of their employing organisations, and those who do not. Further work could exploit the panel structure of the WERS data, where a subsample of employers was interviewed in both 2004 and 2011. This could allow us to control for organisational fixed effects, and to explore how the impact of sharing values changed before and after the global financial crisis, albeit with a smaller sample of employers and employees.

\section{Conclusion}

We have argued that the alignment of values between employers and employees can have a significant effect on employee effort and so on the patterns of hard work observed over an employee's tenure. Applying the theoretical model of Shchetinin (2012) we derive four hypotheses which we test using matched employer-employee data. We find both a career-concerns effect and an effect of shared values leading to increased employee overtime. By estimating relative overtime hours we show that our results are robust to differences in working patterns between occupations. We also show that the tenure pattern of overtime consistent with a career-concerns motivation is not present in employees whose values are aligned with those of their employers.

At the descriptive level we find that twice as many employees in the voluntary sector agree strongly that they share the values of their organisations compared with their counterparts in the private sector. Since our main results also hold while controlling for the voluntary sector we conjecture that employers there need rely less on providing career paths than do employers in the private sector. This is significant in helping to understand how employment contracts, both explicit and implicit, might differ depending on the institutional form of the employer. 
Pro-social motivation is increasingly being understood as having an influence over many elements of the employment relationship, both in formal terms (e.g. through wages) and tacitly (e.g. through effort). Studying employment in this manner allows us to explore the interaction between pecuniary motivation and shared values in compensating workers. Understanding the ways in which motivation can be harnessed also has the potential to increase the efficiency of a range of public services as nonprofit organisational forms are increasingly involved in public-service provision.

\section{Notes}

1. The authors do not distinguish between paid and unpaid overtime hours.

2. In this baseline model the parameter $\theta_{i} \in[0,1]$ is assumed to be common knowledge, i.e. employers are aware of the extent to which employees share their values. Shchetinin (2012) also analyses the case where there is information asymmetry not just about employee talent but also about alignment with the employer's objectives. In such a scenario the employee has an additional incentive to work hard in order to suggest high alignment with the employer's values.

3. The two-period setting is sufficient for demonstrating the presence of career concerns and deriving our hypotheses. Shchetinin (2012, p. 16) also considers $T>2$ periods and demonstrates how career concerns reduce effort in each consecutive period until fading away completely in period $t=$ $T$. See Appendix 7.1 for the derivation of equation (1).

4. In fact career concerns disappear in the final period, here $t=2$.

5. The extent of this "caring" is given by $\theta_{i}$.

6. Details available on request.

7. The tenure categories are: less than 1 year, 1 to less than 2 years, 2 to less than 5 years, 5 to less than 10 years and 10 years or more.

8. The private, public and voluntary sectors are defined according to the formal establishment status of the employer. See Table 5 in Appendix 7.3 for details.

9. The statistics described here are listed in Table 6 in Appendix 7.4 .

10. The variable gross-wage level is coded from 1 to 14 according to the salary categories that employee respondents selected in the WERS questionnaires. These categories were adjusted between 2004 and 2011 to account for inflation in wages. See Table 4 in Appendix 7.2 for details of the salary categories and distributions by year.

11. We are grateful to the editor for a suggestion to discuss the possible impact of differentiated tenure effects by gender, specifically maternity leave, on our results. We discuss this in subsection 5.3.

12. See Appendix 7.5 for the specification with binary controls for tenure as well as a regression on a subsample of employees with a minimum of two years' tenure.

13. Individual employees appear only once in WERS.

14. We are grateful to an anonymous referee for this alternative explanation.

\section{Acknowledgements}

The authors are grateful to the editor and two anonymous reviewers for constructive comments and suggestions. The authors would also like to thank Alex Bryson, Ed Lazear and participants at the 18th Colloquium on Personnel Economics in Vienna as well as colleagues at seminars in Dundee and Stirling for their valuable comments and suggestions to improve the empirical analysis. Further thanks are due to Paul Lambert for useful suggestions on the standardisation of overtime hours. Any errors and omissions are the authors'. The 2004 Workplace Employment Relations Survey (WERS) was jointly sponsored by the Department of Trade and Industry, the Advisory, Conciliation and Arbitration Service, the Economic and Social Research Council (ESRC) and the Policy Studies Institute. The 2011 WERS was jointly sponsored by the Department for Business, Innovation and Skills, ESRC, the Advisory, Conciliation and Arbitration Service, the National Institute of Economic and Social Research (with funds from the Nuffield Foundation) and the UK Commission for Employment and Skills. The fieldwork was conducted by the National Centre for Social Research. The WERS datasets are distributed by the UK Data Archive at the University of Essex.

\section{References}

Akerlof, G. A. (1982). Labor contracts as partial gift exchange. The Quarterly Journal of Economics 97(4), 543-569.

Akerlof, G. A. (1983). Loyalty filters. The American Economic Review 73(1), 54-63.

Akerlof, G. A. and R. E. Kranton (2005). Identity and the economics of organizations. Journal of Economic Perspectives 19(1), 9-32.

Anger, S. (2008). Overtime work as a signaling device. Scottish Journal of Political Economy 55(2), 167-189.

Bell, D. N. F., A. Gaj, R. A. Hart, O. Hübler, and W. Schwerdt (2001). Unpaid overtime working in Germany and the UK. Available at http://ftp.zew.de/pub/zewdocs/div/wwheworkshop/hart.pdf.

Bénabou, R. and J. Tirole (2006). Incentives and prosocial behavior. American Economic Review 96(5), 1652-1678.

Besley, T. and M. Ghatak (2005). Competition and incentives with motivated agents. American Economic Review 95(3), 616-636.

Booth, A. L., M. Francesconi, and J. Frank (2003). A sticky floors model of promotion, pay, and gender. European Economic Review 47(2), 295-322.

Bratti, M. and S. Staffolani (2007). Effort-based career opportunities and working time. International Journal of Manpower 28(6), 489-512.

Buligescu, B., D. De Crombrugghe, G. Menteşoğlu, and R. Montizaan (2009). Panel estimates of the wage penalty for maternal leave. Oxford Economic Papers 61(suppl 1), i35-i55.

Buurman, M., J. Delfgaauw, R. Dur, and S. Van den Bossche (2012). Public sector employees: Risk averse and altruistic? Journal of Economic Behavior \& Organization 83(3), 279-291.

Carpenter, J. and E. Gong (2016). Motivating agents: How much does the mission matter? Journal of Labor Economics 34(1), 211-236.

Dur, R. and R. Zoutenbier (2015). Intrinsic motivations of public sector employees: Evidence for germany. German Economic Review 16(3), 343-366.

Engellandt, A. and R. T. Riphahn (2005). Temporary contracts and employee effort. Labour Economics 12(3), 281-299.

Fama, E. F. (1980). Agency problems and the theory of the firm. Journal of Political Economy 88(2), 288-307. 
Fehrler, S. and M. Kosfeld (2014). Pro-social missions and worker motivation: An experimental study. Journal of Economic Behavior \& Organization 100, 99-110.

Francois, P. and M. Vlassopoulos (2008). Pro-social motivation and the delivery of social services. CESifo Economic Studies 54(1), $22-54$.

Gerhards, L. (2015). The incentive effects of missions: Evidence from experiments with ngo employees and students. European Economic Review 79, 252-262.

Gibbons, R. S. (1987). Piece-rate incentive schemes. Journal of Labor Economics 5(4), 413-429.

Gibbons, R. S. and K. J. Murphy (1992). Optimal incentive contracts in the presence of career concerns: Theory and evidence. Journal of Political Economy 100(3), 468-505.

Glaeser, E. L. and A. Shleifer (2001). Not-for-profit entrepreneurs. Journal of Public Economics 81(1), 99-115.

Gregg, P., P. Grout, A. Ratcliffe, S. Smith, and F. Windmeijer (2011). How important is pro-social behaviour in the delivery of public services? Journal of Public Economics 95(7-8), 758766.

Hart, R. A. (2004). The Economics of Overtime Working. Cambridge: Cambridge University Press.

Holmström, B. R. (1982). Managerial incentive problems - A dynamic perspective. In Essays in Economics and Management in Honor of Lars Wahlbeck. Helsinki: Swedish School of Economics. Reprinted in Review of Economic Studies 66(1), 169-182 (1999).

Landers, R. M., J. B. Rebitzer, and L. J. Taylor (1996). Rat race redux: Adverse selection in the determination of work hours in law firms. The American Economic Review 86(3), 329-348.

Lazear, E. P. (1986). Salaries and piece rates. The Journal of Business 59(3), 405-431.

Manchester, C. F., L. M. Leslie, and T.-Y. Park (2008). Screening for commitment: The effect of maternity leave usage on wages. Mimeo. Unpublished manuscript.

McGovern, P., S. Hill, C. Mills, and M. White (2007). Market, class, and employment. Oxford University Press.

Meglino, B. M. and E. C. Ravlin (1998). Individual values in organizations: Concepts, controversies, and research. Journal of Management 24(3), 351-389.

O'Reilly, C. A. and J. Chatman (1986). Organizational commitment and psychological attachment: The effects of compliance, identification, and internalization on prosocial behavior. Journal of Applied Psychology 71(3), 492.

Pannenberg, M. (2005). Long-term effects of unpaid overtime: Evidence for West Germany. Scottish Journal of Political Economy 52(2), 177-193.

Rose-Ackerman, S. (1997). Altruism, ideological entrepreneurs and the nonprofit firm. Voluntas 8(2), 120-134.

Shapiro, C. and J. E. Stiglitz (1984). Equilibrium unemployment as a worker discipline device. The American Economic Review 74(3), 433-444.

Shchetinin, O. (2012). Motivated agents with career concerns: Signalling skills and organizational involvement. University of Gothenburg Working Papers in Economics No. 524.

Snijders, T. A. B. and R. J. Bosker (2011). Multilevel analysis: An introduction to basic and advanced multilevel modeling (2nd ed.). New York: Sage.

\section{Appendix}

\subsection{Derivation of equation (1)}

This derivation is equivalent to the benchmark case presented by Shchetinin (2012, pp. 5-6). The time structure of the twoperiod model is as follows. In the first period the employer offers a wage for work and the employee chooses a level of effort. At the beginning of the second period the employer offers another wage after which the employee again chooses how much effort to exert. The employer competes with other labour-market opportunities so the wage equals the employee's expected productivity. In the second period the wage thus reflects the knowledge gained from observing the employee's performance in the first period.

Table 3. Order of events in the two-period model

\begin{tabular}{ll}
\hline \hline time & action \\
\hline 1.1 & employer offers wage $w_{i, 1}$ \\
1.2 & employee chooses effort $e_{i, 1}$ \\
2.1 & employer offers wage $w_{i, 2}$ \\
2.2 & employee chooses effort $e_{i, 2}$
\end{tabular}

Equilibrium wages and effort levels are determined by backwards induction. In the second period, the employee chooses effort $e_{i, 2}$ to maximise net expected utility

$$
\begin{aligned}
& \max _{e_{i, 2}} w_{i, 2}+\theta_{i}\left(E\left[y_{i, 2}\right]-w_{i, 2}\right)-C\left(e_{i, 2}\right) \\
\Leftrightarrow & \max _{e_{i, 2}}\left(1-\theta_{i}\right) w_{i, 2}+\theta_{i}\left(\bar{a}+e_{i, 2}\right)-C\left(e_{i, 2}\right) .
\end{aligned}
$$

Equilibrium effort $e_{i, 2}^{*}$ is characterised by the first-order condition

$$
C^{\prime}\left(e_{i, 2}^{*}\right)=\theta_{i}
$$

In the second period the wage, which is fixed, does not affect employee effort. However the employee will work harder, the more important the employer's objectives (expected output net of wage costs) are to her (the higher is $\theta_{i}$ ). Note that if she does not share the same values as her employer $\theta_{i}=0$ then the employee will not exert any effort in the second period due to the lack of incentives. Competition for labour in the employment market leads the employer to offer a wage equal to expected output in the second period, given the output observed in the first period

$$
\begin{aligned}
w_{i, 2}= & E\left[y_{i, 2} \mid y_{i, 1}\right] \\
= & E\left[a_{i}+e_{i, 2}+\varepsilon_{i, 2} \mid y_{i, 1}\right] \\
= & E\left[a_{i} \mid y_{i, 1}\right]+e_{i, 2}^{*} \\
= & E\left[a_{i} \mid a_{i}+e_{i, 1}+\varepsilon_{i, 1}\right]+e_{i, 2}^{*} \\
= & \bar{a}+\frac{\operatorname{cov}\left(a_{i}+e_{i, 1}+\varepsilon_{i, 1}, a_{i}\right)}{\operatorname{var}\left(a_{i}+e_{i, 1}+\varepsilon_{i, 1}\right)} . \\
& \left(a_{i}+e_{i, 1}+\varepsilon_{i, 1}-\bar{a}-e_{i, 1}^{*}\right)+e_{i, 2}^{*} \\
= & \bar{a}+\frac{\sigma_{a}^{2}}{\sigma_{a}^{2}+\sigma_{\varepsilon}^{2}} \cdot\left(a_{i}+e_{i, 1}+\varepsilon_{i, 1}-\bar{a}-e_{i, 1}^{*}\right)+e_{i, 2}^{*}
\end{aligned}
$$

where $e_{i, 1}^{*}$ denotes equilibrium employee effort in the first period. Rearranging, the wage in the second period can be written as 


\subsection{Salary data}

$$
\begin{aligned}
w_{i, 2}= & \frac{\sigma_{\varepsilon}^{2}}{\sigma_{a}^{2}+\sigma_{\varepsilon}^{2}} \cdot \bar{a}+\frac{\sigma_{a}^{2}}{\sigma_{a}^{2}+\sigma_{\varepsilon}^{2}} . \\
& \left(a_{i}+e_{i, 1}+\varepsilon_{i, 1}-e_{i, 1}^{*}\right)+e_{i, 2}^{*} .
\end{aligned}
$$

It follows that the employee can increase her secondperiod wage by exerting a higher level of effort in the first period $\partial w_{i, 2} / \partial e_{i, 1}>0$. Only total output is observable, not individual inputs (ability, effort and noise), so she can signal high innate ability to the employer by working harder in the first period. She will choose a level of effort to maximise the present value of her net expected utility across both time periods:

$$
\begin{aligned}
& \max _{e_{i, 1}} E\left[U_{i, 1}-C\left(e_{i, 1}\right)\right]+\delta \cdot E\left[U_{i, 2}-C\left(e_{i, 2}\right)\right] \\
\Leftrightarrow & \max _{e_{i, 1}} w_{i, 1}-C\left(e_{i, 1}\right)+\theta_{i}\left(y_{i, 1}-w_{i, 1}\right)+ \\
& \delta \cdot E\left[w_{i, 2}-C\left(e_{i, 2}\right)+\theta_{i}\left(y_{i, 2}-w_{i, 2}\right) \mid e_{i, 1}\right] \\
\Leftrightarrow & \max _{e_{i, 1}}\left(1-\theta_{i}\right) w_{i, 1}-C\left(e_{i, 1}\right)+\theta_{i}\left(a_{i}+e_{i, 1}+\varepsilon_{i, 1}\right) \\
& +\delta \cdot\left(1-\theta_{i}\right)\left(\frac{\sigma_{\varepsilon}^{2}}{\sigma_{a}^{2}+\sigma_{\varepsilon}^{2}} \cdot \bar{a}+\frac{\sigma_{a}^{2}}{\sigma_{a}^{2}+\sigma_{\varepsilon}^{2}} .\right. \\
& \left.\left(a_{i}+e_{i, 1}+\varepsilon_{i, 1}-e_{i, 1}^{*}\right)+e_{i, 2}^{*}\right)+ \\
& \delta \cdot \theta_{i}\left(\bar{a}+e_{i, 2}^{*}\right)-\delta \cdot C\left(e_{i, 2}\right) .
\end{aligned}
$$

This optimisation problem reduces to

\begin{tabular}{|c|c|c|c|}
\hline Annual salary & private & $\begin{array}{l}\text { Sector } \\
\text { public }\end{array}$ & voluntary \\
\hline \multicolumn{4}{|l|}{$2004(£)$} \\
\hline $0-2,600$ & 280 & 189 & 37 \\
\hline $2,601-4,160$ & 385 & 171 & 55 \\
\hline $4,161-5,720$ & 513 & 198 & 56 \\
\hline $5,721-7,280$ & 491 & 301 & 77 \\
\hline $7,281-9,360$ & 664 & 331 & 90 \\
\hline $9,361-11,440$ & 981 & 421 & 96 \\
\hline $11,441-13,520$ & 1,160 & 575 & 86 \\
\hline $13,521-16,120$ & 1,478 & 727 & 95 \\
\hline $16,121-18,720$ & 1,247 & 585 & 81 \\
\hline $18,721-22,360$ & 1,437 & 770 & 72 \\
\hline $22,361-28,080$ & 1,386 & 845 & 74 \\
\hline $28,081-35,360$ & 1,099 & 707 & 72 \\
\hline $35,361-45,240$ & 660 & 327 & 35 \\
\hline $45,241-$ & 746 & 185 & 14 \\
\hline \multicolumn{4}{|l|}{$2011(£)$} \\
\hline $0-3,120$ & 230 & 180 & 36 \\
\hline $3,121-5,200$ & 345 & 135 & 65 \\
\hline $5,201-6,760$ & 315 & 157 & 71 \\
\hline $6,761-8,840$ & 359 & 285 & 112 \\
\hline $8,841-11,440$ & 620 & 488 & 128 \\
\hline $11,441-13,520$ & 737 & 454 & 116 \\
\hline $13,521-16,120$ & 811 & 653 & 149 \\
\hline $16,121-19,240$ & 970 & 860 & 171 \\
\hline $19,241-22,360$ & 934 & 760 & 180 \\
\hline $22,361-27,040$ & 1,084 & 792 & 195 \\
\hline $27,041-33,800$ & 1,048 & 853 & 190 \\
\hline $33,801-42,640$ & 813 & 710 & 166 \\
\hline $42,641-54,600$ & 553 & 301 & 95 \\
\hline $54,601-$ & 591 & 188 & 61 \\
\hline
\end{tabular}

$$
\max _{e_{i, 1}}-C\left(e_{i, 1}\right)+\theta_{i} \cdot e_{i, 1}+\delta\left(1-\theta_{i}\right) \cdot \frac{\sigma_{a}^{2}}{\sigma_{a}^{2}+\sigma_{\varepsilon}^{2}} \cdot e_{i, 1}
$$

with equilibrium effort $e_{i, 1}^{*}$ characterised by the first-order condition

$$
C^{\prime}\left(e_{i, 1}^{*}\right)=\theta_{i}+\left(1-\theta_{i}\right) \cdot \delta \cdot \frac{\sigma_{a}^{2}}{\sigma_{a}^{2}+\sigma_{\varepsilon}^{2}} .
$$

Equation (1) is simply the combination of equations (2) and (4) for $t \in\{1,2\}$.
Table 4. Distribution of salaries in the sample

Source: UK Workplace Employment Relations Survey 


\subsection{Sector data}

Table 5. Defining the private, public and voluntary sectors

\section{Private sector}

Public Limited Company (PLC) $\quad 7,505$

Private limited company $\quad 10,907$

Company limited by guarantee $\quad 1,044$

Partnership (including Limited Liability

Partnership) / Self-proprietorship

1,044

Body established by Royal Charter

Co-operative / Mutual / Friendly society

\section{Public sector}

Government-owned limited company / Nationalised

industry / Trading Public Corporation $\quad 1,132$

Public service agency / $\quad 1,271$

Other non-trading public corporation 258

Quasi Autonomous National Government Organisation 146

Local/Central Government (including NHS and

Local Education Authorities)

\section{Voluntary sector}

Trust / Charity 
Table 6. Descriptive statistics (extension to Table 1)

\begin{tabular}{|c|c|c|c|c|c|c|}
\hline \multirow{3}{*}{$\begin{array}{l}\text { Variable } \\
\text { overtime hours }>0 \\
\text { overtime hours }\end{array}$} & \multicolumn{2}{|c|}{ private } & \multicolumn{2}{|c|}{$\begin{array}{l}\text { Sector } \\
\text { public }\end{array}$} & \multicolumn{2}{|c|}{ voluntary } \\
\hline & 0.499 & $(0.500)$ & 0.475 & $(0.499)$ & 0.497 & $(0.500)$ \\
\hline & 3.644 & $(5.878)$ & 3.365 & $(5.959)$ & 3.347 & $(5.387)$ \\
\hline part-time work & 0.207 & $(0.405)$ & 0.312 & $(0.463)$ & 0.357 & $(0.479)$ \\
\hline tenure (years) & 5.784 & $(4.277)$ & 6.697 & $(4.307)$ & 5.707 & $(4.189)$ \\
\hline strongly shared values & 0.123 & $(0.328)$ & 0.146 & $(0.353)$ & 0.229 & $(0.420)$ \\
\hline gross-wage level & 8.525 & $(3.329)$ & 8.505 & $(3.154)$ & 7.889 & $(3.381)$ \\
\hline trade-union member & 0.228 & $(0.420)$ & 0.628 & $(0.483)$ & 0.282 & $(0.450)$ \\
\hline supervisor & 0.342 & $(0.474)$ & 0.341 & $(0.474)$ & 0.370 & $(0.483)$ \\
\hline male & 0.537 & $(0.499)$ & 0.345 & $(0.475)$ & 0.296 & $(0.456)$ \\
\hline aged $16-21$ & 0.068 & $(0.251)$ & 0.015 & $(0.120)$ & 0.035 & $(0.183)$ \\
\hline aged $22-29$ & 0.179 & $(0.384)$ & 0.116 & $(0.320)$ & 0.142 & $(0.349)$ \\
\hline aged $30-39$ & 0.250 & $(0.433)$ & 0.227 & $(0.419)$ & 0.212 & $(0.409)$ \\
\hline aged $40-49$ & 0.252 & $(0.431)$ & 0.323 & $(0.468)$ & 0.267 & $(0.442)$ \\
\hline aged $50-59$ & 0.197 & $(0.398)$ & 0.264 & $(0.441)$ & 0.258 & $(0.437)$ \\
\hline aged $60+$ & 0.054 & $(0.226)$ & 0.055 & $(0.228)$ & 0.088 & $(0.283)$ \\
\hline married or cohabiting & 0.669 & $(0.471)$ & 0.728 & $(0.445)$ & 0.674 & $(0.469)$ \\
\hline single & 0.246 & $(0.431)$ & 0.164 & $(0.371)$ & 0.207 & $(0.406)$ \\
\hline widowed & 0.011 & $(0.104)$ & 0.015 & $(0.123)$ & 0.019 & $(0.138)$ \\
\hline separated & 0.075 & $(0.263)$ & 0.093 & $(0.290)$ & 0.099 & $(0.299)$ \\
\hline dependent children & 0.369 & $(0.483)$ & 0.429 & $(0.495)$ & 0.354 & $(0.478)$ \\
\hline year $=2011$ & 0.429 & $(0.495)$ & 0.518 & $(0.500)$ & 0.649 & $(0.477)$ \\
\hline observations & & 937 & & 148 & & 675 \\
\hline
\end{tabular}

Source: UK Workplace Employment Relations Survey 2004, 2011

Note: Sample standard deviations in parentheses. 


\subsection{Alternative model specifications}

Table 7. Tobit regression with binary controls for tenure

\begin{tabular}{lcc}
\hline \hline & \multicolumn{2}{c}{6} \\
\hline tenure $\in[1,2)$ & 0.094 & $(0.091)$ \\
tenure $\in[2,5)$ & -0.042 & $(0.078)$ \\
tenure $\in[5,10)$ & $-\mathbf{0 . 2 6 6}^{* *}$ & $(0.084)$ \\
tenure $\geq 10$ & $-\mathbf{0 . 4 4 1}^{* *}$ & $(0.085)$ \\
strongly shared values $($ ssv $)$ & 0.205 & $(0.149)$ \\
ssv $\cdot$ tenure $\in[1,2)$ & -0.016 & $(0.220)$ \\
ssv $\cdot$ tenure $\in[2,5)$ & 0.156 & $(0.181)$ \\
ssv $\cdot$ tenure $\in[5,10)$ & 0.150 & $(0.188)$ \\
ssv $\cdot$ tenure $\geq 10$ & $\mathbf{0 . 3 8 9 ^ { * }}$ & $(0.178)$ \\
wage level & $\mathbf{0 . 3 4 8 ^ { * * }}(0.010)$ \\
part-time $(\leq 30$ hours/week $)$ & $\mathbf{0 . 3 1 2}$ & $(0.077)$ \\
year $=2011$ & -0.045 & $(0.058)$ \\
Constant & $-\mathbf{6 . 1 3 7}^{* *}$ & $(0.138)$ \\
Pseudo $R^{2}$ & \multicolumn{2}{c}{0.033} \\
Observations & \multicolumn{2}{c}{37,760} \\
Left-censored observations & \multicolumn{2}{c}{39,248} \\
Employer clusters & \multicolumn{2}{c}{3,618} \\
\hline
\end{tabular}

Notes:

(1) Dependent variable: $\ln \left(\frac{\text { employee overtime hours }}{\text { mean overtime hours for occupation and year }}\right)$.

(2) Standard errors in parentheses, adjusted for clustering by employer.

(3) Additional controls: sector, trade-union membership, foremanship, gender, age group, marital status, dependent children.

Reference group: working in private sector, female, aged $40-49$, married/cohabiting, no dependent children.

$(4)^{* *}\left({ }^{*}\right)$ denotes statistically significant difference from zero at the $1 \%(5 \%)$ level.
Table 8. Tobit regression, employees with minimum tenure of 2 years

\begin{tabular}{lcc}
\hline \hline & \multicolumn{2}{c}{7} \\
\hline tenure & $\mathbf{- 0 . 0 4 7}$ & $(0.008)$ \\
strongly shared values & 0.224 & $(0.145)$ \\
strongly shared values $\cdot$ tenure & 0.027 & $(0.017)$ \\
wage level & $\mathbf{0 . 3 5 5}^{* *}$ & $(0.012)$ \\
part-time $(\leq 30$ hours/week) & $\mathbf{0 . 1 7 0}^{*}$ & $(0.084)$ \\
year $=2011$ & $-0.077 \quad(0.064)$ \\
Additional controls & \multicolumn{2}{c}{ yes } \\
Constant & $-\mathbf{6 . 0 0 4}^{* *}(0.152)$ \\
Pseudo $R^{2}$ & \multicolumn{2}{c}{0.035} \\
Observations & \multicolumn{2}{c}{28,388} \\
Left-censored observations & \multicolumn{2}{c}{14,404} \\
Employer clusters & \multicolumn{2}{c}{3,509} \\
\hline
\end{tabular}

\section{Notes:}

(1) Dependent variable: $\ln \left(\frac{\text { employee overtime hours }}{\text { mean overtime hours for occupation and year }}\right)$.

(2) Standard errors in parentheses, adjusted for clustering by employer.

(3) Additional controls: sector, trade-union membership, foremanship, gender, age group, marital status, dependent children.

Reference group: working in private sector, female, aged $40-49$, married/cohabiting, no dependent children.

$\left.(4) * *{ }^{*}\right)$ denotes statistically significant difference from zero at the $1 \%(5 \%)$ level. 